\title{
Campylobacter fetus subespecie yeyuni en lactantes con síndrome diarréico agudo
}

\author{
Dr. Gastón Duffau T. ${ }^{3}$ Dra. Fosanna Lagos Z. ${ }^{1}$ Dr. Julio Garcia M. ${ }^{2}$ T.M. Aurora Maldonado B.4
}

\section{Campylobacter fetus subespecimen jejum in infants with acute diarheic syndrome}

\begin{abstract}
A bacteriological research that included the finding of Campylobacter Fetus Subespectmen Jejum was carried out in 42 patients hospitalized because of diarthea at the Infants Departament af the Roberto del Río Hospital.

The isolation of the genmen is reported in 6 of them, the culture technique and the characteristics of the clinical features of these patients are described.

An epidemiological and clinical description of Enteritis due to Campylobacteria extracted from a bibliographic revision is included.
\end{abstract}

Los primeros coprocultivos positivos para Campylobacterias fueron reportados en Bélgica hace 9 años. ${ }^{1,} 2$ Posteriomente Skirrow repitió estos hallazgos y logró simplificar el método y aumentar la selectividad del medio de cultivo. ${ }^{3}$ Desde la publicación de sus trabajos en 1977, frecuentes informes provenientes de diferentes países del mundo notifican el hallazgo de Campylobacter Fetus subespecie Yeyuni en pacientes con diarrea.

En la actualidad, la participación de este germen en cuadros diarreicos es ampliamente aceptada y, aunque la real magnitud del problema no está aún establecida, en algunas áreas se les considera la primera causa de diartea de etiología infeccios $a^{4}$ y en otras se ha descrito brotes, epidémicos de hasta 2.000 casos.

Con el propósito de conocer la importancia relativa de Campylobacter Yeyuni en nuestro medio, se planificó una investigación prospectiva en 100 pacientes hospitalizados por diarrea en el Servicio de Lactantes del Hospital Roberto del Río de Santiago. El estudio de cada enfermo incluye la búsqueda de las siguientes etiologías:

- Parásitos

- Rotavirus

- Salmonella

- Shiguella

- E. Coli enteropatógeno (serotipos clásicos)
- Campylobacter Fetus subespecie Yeyuni

- Yersinia enterocolítica

Hasta la fecha de la presente comunicación se han reunido 42 casos; en 6 de ellos se demostró la presencia de Campylobacter Yeyuni y en 1 se aisló Yersinia enterocolítica.

\section{MATERIAL Y METODICA SEGUIDA EN LA INVESTIGACION BACTERYOLOGICA}

La investigación, iniciada el $1^{\circ}$ de Julio de 1981, considera entre otros aspectos, la búsqueda de las etiologías enumeradas en 100 pacientes elegidos al azar entre los ingresados al Servicio de Lactantes del Hospital Roberto de Río con diagnóstico de Sindrome Diarreico Agudo.

Las muestras fecales para estudios bacteriológgicos son obtenidas por estimulación anal durante el primer día de hospitalización de los pacientes y enviadas inmediatamente al Instituto de Salud Pública de Chile, en frascos cerrados, sin medio de transporte. La siembra de las muestras fecales se realiza antes de transcurridas 3 horas desde su emisión.

Para el cultivo de Campylobacter Yeyuni se utiliza medio de Campy-BAP con antibióticos, en jarra Gaspac sin catalizador, a temperatura de $42^{\circ} \mathrm{C}$. Para Yersinia Enterocolítica se usó Buffer fosfato a $5^{\circ} \mathrm{C}$.

\section{RESULTADOS}

En 6 de los 42 pacientes hasta ahora investigados se demostró la presencia de Campylobacter Fetus subespecie Yeyumi con la técnica bacteriológica

\footnotetext{
1 Becada Pediatria. Hosp. R del Río.

2 Inst. de Salud Pública de Chile (Bacteriológico).

3 Serv. de Lactantes. Hosp. R. del Fio.

4 Inst. de Salud Pública de Chile (Bacteriológico).
} 


\section{Figura 1}

Metódica de estudio bacteriologico.

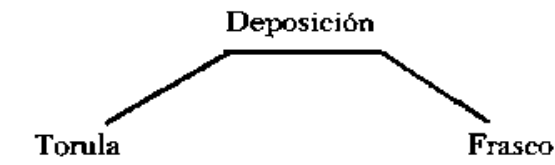

[Cary - Blair]

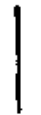

Yersinia EC

Cultivo Corriente

Campylobacter

Figura 2

Campylobacter

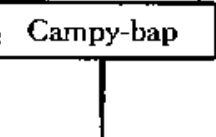

Inculbación en jarra Gas-pack sin catalizador $\mathrm{A} 42^{\circ} \mathrm{C}$ por 24 horas.

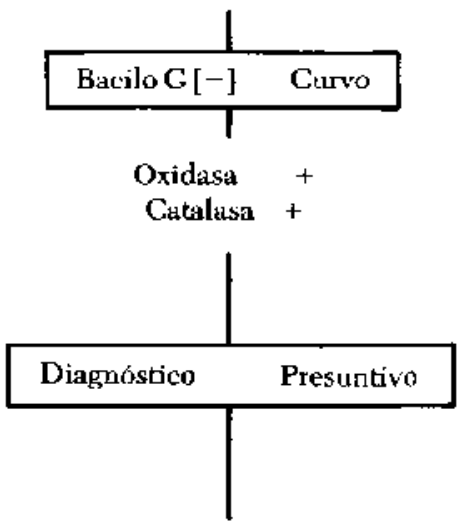

Pruebas bioquímicas de confirmación.

descrita. El cuadro clínico de estos pacientes se resume en la Figura 3.

\section{COMENTARIO}

El género Canpylobacter, de la tamilia de las Espiraláceas, agrupa en la actualidad a una serie de microorganismos que inicialmente se clasilica- ron junto a los Vibrios por su semejanza morfológica con ellos. ${ }^{6}$ Iniciada la segunda década de este siglo, la investigación de estas bacterias motivó especial preocupación en el ámbito de la Medicina Veterinaria, donde se les reconoce desde hace mucho como agentes etiológicos de abortos sépticos y esterilidad en animales domésticos.

En Medicina Humana, la literatura previa a 1970 reúne no más de un centernar de informes que sugieren su posible acción patógena para el hombre, relacionándolos con infeccioses sistémicas (gérmenes aislados de la sangre), con muy variadas manifestaciones clínicas y predominantemente en huêspedes inmunodeprimidos. ${ }^{8}$ Aunque ya en 1957 se sospechó su participación en cuadros diarreicos en individuos previamentes $\operatorname{sanos}^{9,} 10,11,12,13$ ha sido sólo en los últimos cuatro años que el perfeccionamiento de nuevas técnicas bacteriológicas ha pennitido aislarlos con facilidad en las deposiciones ${ }^{6}$ y evidenciar su importancia como agentes enteropatógenos en diferentes grupos etáreos y su amplia distribución geográfica. $^{2,3,4,5,8,14,16,17}$

\section{EPIDEMIOLOGIA Y CUADRO CLINICO}

La Entiritis por Campylobacter Yeyuni afecta a individuos de cualquier edad, pero la mayor acuinulación de casos parece encontrarse en el grupo de 1 a 5 años. ${ }^{3,} 14$ Por lo general se desconoce la fuente de infección y aún no existe consenso respecto al modo de transmisión de la enfermedad: varios autores han publicado evidencias a favor de una transmisión persona a persona ${ }^{15,}{ }^{16}$ pero no existen suficientes pruebas para descartar la posibilidad de contagio por contactos no humanos. ${ }^{3,17}$

Los estudios con inoculación de cultivos puros en voluntarios sanos revelan que el período promedio de incubación fluctua entre 3 y 5 días con un rango que va de 2 a 11 dias. La intensidad de los síntomas varia de un enfermo a otro, pudiendo manifestarse como un cuatro de Enteritis leve $y$ de corta duración o adquirir las caracteristicas de una infección Enteral severa.

La diarrea puede ir precedida por un lapso de 1 a 3 dias de dolor abdominal y fiebre. Inicialmente la deposición es líquida y con frecuencia se observa la aparición de estrías de sangre 2 a 4 días después de instalada. El dolor abdominal periumbilical es un elemento bastante constante; suele ser intenso y, cuando antecede a la aparición de la 
Figura N. ${ }^{\circ} 3$

Cuadro clínico en 6 pacientes con aislamiento de

Campylobacter Fehus S-SP Jejuni.

\begin{tabular}{|c|c|c|c|c|c|c|}
\hline $\begin{array}{l}\mathrm{C} \\
\mathrm{a} \\
\mathrm{s} \\
\mathrm{o}\end{array}$ & $\begin{array}{l}\text { Edad } \\
\text { Sexo } \\
\text { E. Nutr. }\end{array}$ & $\begin{array}{c}\mathrm{T}^{0} \text {. al Ingreso } \\
\text { Rectal }\end{array}$ & Dias de fiebre & Dep. al Ingreso & Días de diarrea & Complicaciones \\
\hline I & $\begin{array}{l}3 \mathrm{~m} 27 \mathrm{~d} \\
\text { Mase. } \\
\text { Eutrófico }\end{array}$ & $38^{\circ} \mathrm{C}$ & 3 & Líquidas & 7 & NO \\
\hline 2 & $\begin{array}{l}4 \mathrm{~m} 15 \mathrm{~d} \\
\text { Fem. } \\
\text { Eutrofico }\end{array}$ & $37,4^{\circ} \mathrm{C}$ & 0 & Liquidas & 6 & No \\
\hline 3 & $\begin{array}{l}3 \mathrm{~m} \\
\text { Masc. } \\
\text { Eutrófico }\end{array}$ & $39^{\circ} \mathrm{C}$ & 1 & $\begin{array}{l}\text { Liquidas } \\
\text { con mucus }\end{array}$ & 6 & No \\
\hline 4 & $\begin{array}{l}5 \mathrm{~m} \mathrm{22d} \\
\text { Masc. } \\
\text { Eutrofico }\end{array}$ & $40,2^{\circ} \mathrm{C}$ & 3 & Líquidas & 4 & No \\
\hline 5 & $\begin{array}{l}5 \mathrm{~m} \\
\text { Masc. } \\
\text { Eutrófico }\end{array}$ & $38,2^{\circ} \mathrm{C}$ & 3 & Liquidas & 3 & NO \\
\hline 6 & $\begin{array}{l}\text { la } 3 \mathrm{~m} \\
\text { Masc. } \\
\text { Eutrofico }\end{array}$ & $38^{\circ} \mathrm{C}$ & 3 & Líquidas & 4 & $\begin{array}{l}\text { Shock Hipovol. } \\
\text { Acidosis Met. }\end{array}$ \\
\hline & Promedio & $38,5^{\circ} \mathrm{C}$ & 2 días & & 5 días & \\
\hline
\end{tabular}

diarrea, no es raro que simule cuadros de abdomen agudo quirúrgico. La fíebre, aunque variable en su magnitud y duración, es signo casi infaltable y generalmente el más precoz. Los vómitos y la deshidratación son poco frecuentes, aún en ninos pequeños.

Habitualmente los síntomas no duran más de una semana, al cabo de la cual los enfemmos no tratados continúan elininando el germen por periodos promedios de 15 a 20 días que pueden prolongarse hasta 8 semanas. ${ }^{3,6,8}$

El mecanismo patogénico de la Entiritis por Campylobacter Yeyuni continua sin aclararse. Las experiencias realizadas por Guerrant. ${ }^{18}$ no han logrado demostrar que estos gérnenes produzcan enterotoxinas o posean capacidad invasora.

En estudios in-vitro el Campylobacter Yeyuni ha resultado sensible a Eritromicina, Gentamicina, Furazolidina, Tetraciclina, Doxicilina y Cloranfenicol; la Eritromicina es el antibiótico de elección según la mayoría de los autores, $3,4,8$

\section{CONSIDERACIONES}

El hallazgo de Campylobacter Yeyuni en 6 de los 42 casos estudiados, parece anticipar que este agente, al igual que en otras áreas geográficas, ocupa en nuestro medio un lugar importante entre las etiologias infecciosas de diarrea. Los rasgos clínicos, epidemiológicos y los problemas de salud pública susceptibles de presentarse a raiz de Ios casos no tratados, sugieren la necesidad de incluir la investigación de los pacientes con Síndrome Diarreico Agudo.

\section{RESUMEN}

En 42 pacientes hospitalizados por diarrea en el Servicio de Lactantes del Hospital Roberto del Río, se efectuó una investigación bacteriológica que incluyó la búsqueda de Campylobacter Fetus sub-especie Yeyuni. 
Se notifica el aislamiento del germen en 6 de ellos; se describe la técnica de cultivo y las características del cuadro clínico de estos enfermos.

Se incluye una descripción Epidemiológica y clínica de la Enteritis por Campylobacterias, extraída de la bibliografia revisada al respecto.

\section{REFERENCIAS}

I Debeyser, Gassuin-Detrain, Butzer and Stembon. Acute enterites due to related Vibrio: lirst positive stool cultures. J. of Infex:t Disease. 125: 390-392, 1972.

${ }^{2}$ Butaler, Debeyser, Gissuin-Detroin and Dekoen. Related Vibrio in stwol. J. Pediatric 82: 493, 1975.

${ }^{3}$ Skimow. Campvlobacter Enteritis, a new disease. Br. nued, J. 2; 11, 1979 .

4 Kamati and Fleming. Cumpylobacter Enteritis in childrens. J. Pediatrics 94: 527, 1979.

${ }^{5}$ Morbidty and mortalty weebly upont. 27: 226, Julio-7, 1978 .

${ }^{6}$ Raymond L. Kaptan. Cumpylobacter. Bergey's Mamual of Determinative Bacteriology. 19: 235-242, 1981.
${ }^{7}$ Sinith, Theobeid. Spirilla Associated with disease of the fetal membranes in cattle. J. Exper. Med. 28: 701-719, 1918.

${ }^{8}$ Retting. Campylobacter infections in human beings. J. Pediatrics 94: 855-864, 1979.

${ }^{9} \mathrm{King}$ Elizabeth. Human infections with vibrio fetus and a closely related vibrio. J. of infect. disease 101: $119-128$, 1957.

${ }^{10} \mathrm{King}$ Elbabeth. The laboratory recognition of vibrio fetus and a closely related vibrio isolated from cases of human vibriosis. ANN, N.Y. Aced. Sci. 98: 700-711, 1962.

11 Mondel, Curtis. Acute dysentery syndrome caused by vibrio fetus J.A.M.A. 185: 536-539, 1963.

${ }^{12}$ Kahler, Sheldon. Vibrio fetus infection in man. The new England Journal of Med. 268: 1218-1222, 1960.

${ }^{13}$ Wheeley and Bonchers. Vibrionic enterites in infants. Am. J. Dis. Child. 101: 60, 1961.

14 Tanner and Bulth. Campylobacter Enteritis. Bг. J. Med. 2: 579, 1977.

15 Anonimo. Campylobacter infections in Britain 1977 Br. Med. J. 1: $1357,1978$.

${ }^{16}$ Blosser, Waldman, Bamet and Erhandsoan. Outbrealos of Campylobacter Enteritis in two extended farnilies: Evidence tor person -to- person transmission. J. of Ped. $98: 254257,1981$.

${ }^{17}$ Anonimo. Campylobacter Enteritis Lancet. 2: 270, 1978.

${ }^{18}$ Guemour, Lahio, Winn and Raberts. Campylobacterios is in man: Pathogenic mechanisms and review of 91 blood-streans infections. Am. J. Med. 65: 584, 1978. 